\title{
Commentary: Better late than never!
}

\author{
Antonio M. Calafiore, $\mathrm{MD},{ }^{\mathrm{a}}$ and Michele Di Mauro, $\mathrm{MD}, \mathrm{PhD}^{\mathrm{b}}$ \\ From the ${ }^{\mathrm{a} D e p a r t m e n t}$ of Cardiac Surgery, Pope John Paul II Foundation, Campobasso, Italy; and ${ }^{\mathrm{b} H e a r t}$ Depart- \\ ment, SS Annunziata Hospital, Chieti, Italy. \\ Disclosures: Authors have nothing to disclose with regard to commercial support. \\ Received for publication Oct 18, 2018; accepted for publication Oct 18, 2018; available ahead of print Nov 27 , \\ 2018. \\ Address for reprints: Antonio M. Calafiore, MD, Department of Cardiac Surgery, Pope John Paul II Foundation, \\ Largo Agostino Gemelli, 1, 86100 Campobasso CB, Italy (E-mail: am.calafiore@gmail.com). \\ J Thorac Cardiovasc Surg 2019;158:438-9 \\ $0022-5223 / \$ 36.00$ \\ Copyright $\odot 2018$ by The American Association for Thoracic Surgery \\ https://doi.org/10.1016/j.jtcvs.2018.10.095
}

There is evidence that patients undergoing coronary artery bypass graft $(\mathrm{CABG})$ procedure have increased platelet activity, becoming hypercoagulable during the postoperative period $^{1}$ and showing a significant increase of spontaneous platelet aggregation and platelet hyperreactivity to antiplatelet dual therapy. This can be due to substantial changes in platelet messenger RNA before versus after cardiopulmonary bypass, with consequent messenger RNA protein expression level alterations that cause platelet defect after cardiopulmonary bypass. ${ }^{2}$ This prothrombotic state is increased to higher levels during the first 24 hours after surgery $^{3}$ and can last as late as 30 days after surgery. ${ }^{4}$ The use of an antiplatelet agent, such as aspirin, either before and immediately after surgery, was an attempt to reduce the consequences of a problem that could lead to occlusion of grafts, mainly venous. It was demonstrated that aspirin reduces early mortality and incidence of acute myocardial infarction $^{5}$ and improves patency rate after CABG. ${ }^{6}$ Aspirin, however, has some drawbacks. There is transient impairment in its antiplatelet effect after CABG related to increased platelet turnover caused by the inflammatory process. This could be responsible for the high risk of occlusive thrombosis. ${ }^{7}$ Moreover, around $50 \%$ of patients show reduced postoperative responsiveness to $\operatorname{aspirin}^{8}$ and reduced platelet reactivity has been demonstrated to be a risk factor for recurrent cardiovascular events during follow-up. ${ }^{9}$ The addition of clopidogrel produced better results in terms of venous graft patency rate, ${ }^{10}$ but clopidogrel-a prodrug-has some limitations and was demonstrated to be ineffective in close to $30 \%$ of patients, ${ }^{11}$ limiting the benefit of dual antiplatelet therapy. Finally, the benefit of ticagrelor plus aspirin was shown in a randomized trial that reported improved patency rate of venous grafts. ${ }^{12}$ Similar results were reported by a smaller randomized trial comparing ticagrelor plus aspirin to clopidogrel plus aspirin. ${ }^{13} \mathrm{Xu}$ and colleagues ${ }^{14}$ demonstrate that the basis of a better outcomes in patients treated with ticagrelor plus aspirin are faster onset of action and a higher peak of platelet inhibition compared with clopidogrel plus aspirin.

\section{References}

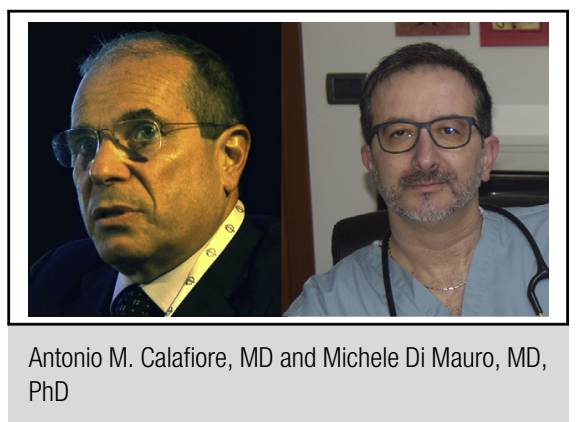

Central Message

Ticagrelor plus aspirin shows faster onset of action and a higher peak of platelet inhibition compared with clopidogrel and aspirin, which leads to better outcomes in patients with CABG.

See Article page 430 .

Since the beginning of $\mathrm{CABG}$ procedures, surgeons have focused on the technical aspects of the anastomoses and on the strategy of grafting, paying little attention to the influence of an adverse biological environment on the graft itself. Instead, cardiologists tried to fight the biological response to the foreign material deployed into the coronary artery, achieving progressively greater results. It is time to realize that coronary surgery is not only an artistic issue; that is, performing a perfect anastomosis is not the entire equation, but only part of it. Finally, we are moving in the right direction. Better late than never!

1. Bochsen L, Rosengaard LB, Nielsen AB, Steinbruchel DA, Johansson PI Platelet hyperreactivity in response to on- and off-pump coronary artery bypass grafting. J Extra Corpor Technol. 2009;41:15-9.

2. Mukai N, Nakayama Y, Ishi S, Ogawa S, Maeda S, Anada N, et al. Changes in microRNA expression level of circulating platelets contribute to platelet defect after cardiopulmonary bypass. Crit Care Med. 2018;46:e761-7.

3. Van Poucke S, Stevens K, Wetzels R, Kicken C, Verhezen P, Theunissen M, et al. Early platelet recovery following cardiac surgery with cardiopulmonary bypass. Platelets. 2016;27:751-7.

4. Parolari A, Mussoni L, Frigerio M, Naliato M, Alamanni F, Galanti A, et al. Increased prothrombotic state lasting as long as one month after on-pump and off-pump coronary surgery. J Thorac Cardiovasc Surg. 2005;130:303-8.

5. Aboul-Hassan SS, Stankowski T, Marczak J, Peksa M, Nawotka M, Stanislawski R, et al. The use of preoperative aspirin in cardiac surgery: a systematic review and meta-analysis. J Card Surg. 2017;32:758-74.

6. Musleh G, Dunning J. Does aspirin $6 \mathrm{~h}$ after coronary artery bypass grafting optimise graft patency? Interact Cardiovasc Thorac Surg. 2003;2:413-5.

7. Arazi HC, Doiny DG, Torcivia RS, Grancelli H, Waldman SV, Nojek C, et al. Impaired anti-platelet effect of aspirin, inflammation and platelet turnover in cardiac surgery. Interact Cardiovasc Thorac Surg. 2010;10:863-7. 
8. Kempfert J, Anger K, Rastan A, Krabbes S, Lehmann S, Garbade J, et al. Postoperative development of aspirin resistance following coronary artery bypass. Eur J Clin Invest. 2009;39:769-74.

9. Sofi F, Marcucci R, Gori AM, Abbate R, Gensini GF. Residual platelet reactivity on aspirin therapy and recurrent cardiovascular events - a meta-analysis. Int $J$ Cardiol. 2008;128:166-71.

10. Nocerino AG, Achenbach S, Taylor AJ. Meta-analysis of effect of single versus dual antiplatelet therapy on early patency of bypass conduits after coronary artery bypass grafting. Am J Cardiol. 2013;112: 1576-9.

11. Di Dedda U, Ranucci M, Baryshnikova E, Castelvecchio S. Thienopyridines resistance and recovery of platelet function after discontinuation of thieno- pyridines in cardiac surgery patients. Eur J Cardiothorac Surg. 2014;45: 165-70.

12. Zhao Q, Zhu Y, Xu Z, Cheng Z, Mei J, Chen X, et al. Effect of ticagrelor plus aspirin, ticagrelor alone, or aspirin alone on saphenous vein graft patency 1 year after coronary artery bypass grafting: a randomized clinical trial. JAMA 2018;319:1677-86

13. Saw J, Wong GC, Mayo J, Bernstein V, Mancini GB, Ye J, et al. Ticagrelor and aspirin for the prevention of cardiovascular events after coronary artery bypass graft surgery. Heart. 2016;102:763-9.

14. Xu F, Feng W, Zhou Z, Zhang Y, Diao X, Hu S, et al. Antiplatelet effects of ticagrelor versus clopidogrel after coronary artery bypass graft surgery: a single center randomized controlled trial. J Thorac Cardiovasc Surg. 2019;158:430-7.e4. 